\title{
Teacher reflection: The use of visual tools in mathematics classrooms
}

\begin{abstract}
Author:
Jayaluxmi Naidoo $^{1}$

Affiliation:

${ }^{1}$ School of Education, Mathematics and Computer Science Education Cluster, University of KwaZulu-Natal, South Africa

Correspondence to:

Jayaluxmi Naidoo

Email:

naidooj2@ukzn.ac.za

Postal address:

Private Bag X03, Ashwood

3605, South Africa

Dates:

Received: 23 Sept. 2011

Accepted: 17 June 2012

Published: 21 Aug. 2012

How to cite this article: Naidoo, J. (2012). Teacher reflection: The use of visual tools in mathematics classrooms. Pythagoras, 33(1), Art. \#54, 9 pages. http://dx.doi.org/10.4102/ pythagoras.v33i1.54
\end{abstract}

C 2012. The Authors. Licensee: AOSIS OpenJournals. This work is licensed under the Creative Commons Attribution License.
Research has shown that the use of visual tools in mathematics classrooms is beneficial, but what we do not know is how South African teachers negotiate the use of visual tools (e.g. diagrams, gestures, the use of colour, et cetera) in classrooms. Research was conducted with six 'master teachers' to explore the use of visual tools. Master teachers in this study are expert teachers identified by the KwaZulu-Natal Department of Education. They are experienced teachers with the potential to mentor new teachers. Master teachers were asked to complete a questionnaire, and they were observed and recorded whilst teaching mathematics lessons. Each master teacher was observed at least three times. All the video recordings were analysed, after which each master teacher was interviewed. After each master teacher interview had been analysed, one focus group interview was conducted with learners at each school. The study was undertaken within a qualitative, interpretive paradigm. The study was framed within Schön's theory of teacher reflection. The findings suggest that each master teacher incorporated the use of visual tools in order to make mathematical concepts easier to understand for the learners. For example, one master teacher used a stick with coloured rubber bands to teach rotation about a point; another master teacher used various colours and lines on an interactive smart board to teach number patterns and a third used hand gestures to demonstrate the direction of the gradient of a line. Interview data suggest that the incorporation of such visual tools came about as a result of teachers' reflecting in action. These findings are important for advancing teacher and curriculum development.

\section{Introduction}

Although 18 years have passed since the first democratic elections in South Africa, schools are still unequally resourced (Chisholm \& Sujee, 2006; Soudien, 2004). Schools differ largely in terms of human resources (the number of personnel at each school), physical resources (infrastructure, desk, chairs, classrooms, etc.) and teaching resources (equipment, textbooks, black or white boards, etc.). Mathematics teachers, especially, are sceptical about the feasibility of teaching the same curriculum within the same time frame to all learners (Naidoo, 2006), regardless of the inequitable distribution of resources (Adler, 2001; Reddy, 2005). Despite their frustration some teachers with limited resources nevertheless manage to assist their learners in grasping complex concepts in mathematics.

This study seeks to explore the following two research questions:

1. Why do master teachers use visual tools in mathematics classrooms?

2. How do master teachers use visual tools in mathematics classrooms?

Visual tools in this study refer to diagrams, pictures, transparencies, mathematics manipulatives, gestures, and the use of colour.

\section{The teaching and learning of mathematics in South Africa}

Education reformers in South Africa are concerned about mathematics teaching in South Africa because of the apparent inability of South African learners to compete successfully with their peers from other countries in global mathematics tests (Howie, 2003; Reddy, 2005). This concern emanates from the reality that society requires mathematical knowledge in order to survive and prosper, and that South African society is far behind in attaining this knowledge.

Recognising that education can contribute to positioning students on an equal level (Freire, 1985), the Department of Education (DOE) in South Africa has urged South African learners to become 'critical citizens' in a mathematically democratic society (DOE, 2003a, pp. 1-7). The underlying premise is that if learners are well educated, especially in a gatekeeper subject such as mathematics, they will be able to move up the 'social ladder'. All South African learners are required to select either Mathematics or Mathematical Literacy as a school subject in Grade 10 and to continue with one of these subjects until the end of their school life. 
The Mathematics curriculum requires the teaching of pure mathematical concepts. In the Further Education and Training Phase, learners are exposed to mathematical experiences that provide them with many opportunities to develop their mathematical reasoning and creative skills (Department of Basic Education, 2011a). The intention of the Mathematics curriculum is to prepare learners for abstract mathematics, which they will encounter in further mathematical studies in higher education.

The Mathematical Literacy curriculum focuses on teaching concepts that are required for 'everyday life situations'. The educational goal of this subject is to enable the learner to become an independent individual capable of contributing to and participating in the workforce of a developing democracy (DOE, 2003b). Furthermore, according to the Mathematical Literacy policy document (Department of Basic Education, 2011b), the teaching and learning of Mathematical Literacy ought to provide learners with opportunities to analyse and devise mathematical ways of solving 'authentic, everyday problems'.

\section{Strategies to promote mathematics and science in South African schools}

Due to the global demand for an improvement in mathematics and science, the DOE in South Africa promoted a national approach to improve participation and performance in mathematics and science education (Reddy, 2005). Part of this approach was the identification of Dinaledi schools nationally. Dinaledi schools are considered 'Star Schools' in South Africa. They were identified after discussions in 2000 on ways to promote the participation and performance of Black learners and female learners in mathematics and science. Initially, 102 schools were identified (Kahn, 2004). In December 2008 there were 500 Dinaledi schools throughout South Africa, 88 of which were located in KwaZulu-Natal (KZN).

Dinaledi schools were provided with resources such as calculators, computers, text books and educational wall charts (DOE, 2008). To further the aims of this approach, the KZN DOE also announced that 120 'master teachers' would be appointed, and that an additional 2400 master teachers would be identified (Makapela, 2007). Selected teachers from each Dinaledi school were invited to professional development workshops in Mathematics, Physical Sciences and Life Sciences. From this cohort of teachers, master teachers in mathematics and science were trained and afterwards professionally supported by subject specialists employed by the DOE. The focus of the support and training was not necessarily on the use of visual tools but on improving teachers' content knowledge in mathematics and science, improving the teaching of mathematics and science and enhancing learner performance in mathematics and science. In South Africa, master teachers serve the same purpose as a mentor or expert teacher. They are senior teachers with the potential to mentor new teachers. The teachers observed in this study were master teachers.

\section{The use of visual tools in the classroom}

The master teachers in the study often used visual tools unknowingly in their classes, for example when they resorted to the use of gestures, colour, lines and symbols. Additionally, this study indicated that the master teachers often used visual tools with the intention of assisting learners to grasp abstract concepts in order to support and improve mathematical conceptual knowledge development. This is supported by Elia and Philippou (2004), who claimed that visual tools play an important role in communicating mathematical ideas and supporting the process of reflection. It also confirms the fact that teachers' tacit knowledge, professional development and beliefs concerning the teaching and learning of mathematics influence the way in which they teach mathematics (Remillard, 2005).

Roodt and Conradie (2003) showed that the use of different approaches to the same problem enriches both learners and teachers. Good teachers often use symbols, colour, diagrams and gestures in the classroom as an alternative to the routine approach of 'talk and chalk' teaching. The use of colour and other visual tools creates an exciting and interesting mathematics classroom (Naidoo, 2011a). More approaches which encourage learners to be active and allow them the opportunity to demonstrate the extent of their thinking and creativity are therefore needed (Barnes, 2005). Stokes (2000) suggested that the use of visual tools assists in uncovering the role that visual reasoning plays in solving problems in mathematics. This leads to interesting results in the teaching and learning of mathematics. Visual tools may also be used as a starting point to achieve interactive and stimulating learning environments (Breen, 1997). In these learning environments, learners are able to interact easily with abstract concepts.

\section{Theoretical framework}

In order to consider the two research questions, we first need to consider some of the theory related to teachers' practices. This study was framed within Schön's theory of teacher reflection and is based on the premise that a good teacher continuously reflects on his or her teaching. Reflection is a process of reviewing the experience of teaching in order to describe, analyse, evaluate and inform learning about teaching (Preen, 2007). Schön defined two types of reflection: reflection-in-action and reflection-on-action (Schön, 1983, 1987). Reflection-in-action refers to the teacher's ability to reflect during a specific lesson rather than after the lesson. This presents a dynamic approach in the teaching and learning process. In contrast, reflection-on-action involves thinking about and reviewing the lesson after the lesson has been concluded. This allows the teacher the prospect of evaluating and commenting on the lesson. Teachers ought to learn from their own practical experience. In doing so, they can either engage in shallow problem solving processes entrenched in traditional norms, or (preferably) engage in a deeper level of problem solving which is more meaningful and challenging (Schön, 1983). 
Through this reflective process, a good teacher recognises that teaching is not a display of knowledge but a process which includes identifying an area of learning and deciding on interventions that will foster learning in this area (Ursano, Kartheiser \& Ursano, 2007). Teachers are required to know how different concepts are interconnected so that, as the mathematics lesson unfolds, they can rectify any misconceptions learners may have (Ball, Lubienski \& Mewborn, 2001). In addition, mathematics teachers should comprehend the progression of concepts across grades as well as the appropriate use of context. The choice of substantial and applicable contexts, based on anecdotal experience, is necessary when teaching mathematics to ensure effective teaching and learning. Learning is seen as a way of developing knowledge within meaningful contexts (Handal \& Bobis, 2004). For contexts to be meaningful, the learners ought to be able to relate to these contexts. Essentially, social contexts that are conducive to learning ought to be created, because the process of learning is itself both social (Putnam \& Borko, 2000; Wentzel, 2002) and cognitive.

\section{Methodology Introduction}

The purpose of this study was to explore master teachers' use of visual tools in mathematics classrooms. Data were collected by means of various research methods so that the research questions could be considered. These methods included administering a master teacher questionnaire (MTQ), Grade 11 mathematics lesson observations, video recordings of the observed lessons, master teacher interviews (MTI), and a focus group interview (FGI) with Grade 11 learners. During the lesson observations a video camera was focused on the master teacher. The camera followed the master teacher throughout the lesson and captured all visual tools used during each observed lesson. This study was located within an interpretive paradigm.

\section{Participants}

\section{Master teachers}

Forty-five master teachers teaching at forty-five different Dinaledi schools in KZN, South Africa were invited to participate in the study. The reason for selecting master teachers was that they were experienced teachers who had shown evidence of being able to assist learners to produce good results in the Grade 12 Mathematics examination. The teacher selection was based on the grade they taught, convenience and accessibility. Twenty master teachers accepted the invitation. The selection of the master teachers for the pilot and main study was random. Ten master teachers were selected for the pilot study. The remaining ten participated in the main study. A further selection was done before the final sample of six master teachers was chosen.

The six master teachers taught at schools in different social milieus. The schools differed with respect to location, context and access to resources. There were three male teachers and three female teachers in the final sample. Some information about the master teachers participating in the study is given in Table 1.
TABLE 1: The master teachers in the final sample.

\begin{tabular}{llcc}
\hline Teacher & Name of school & $\begin{array}{c}\text { Teaching experience } \\
\text { (years) }\end{array}$ & $\begin{array}{c}\text { Teacher qualification } \\
\text { (Number of } \\
\text { postgraduate degrees) }\end{array}$ \\
\hline Dean & Daisy & 26 & 1.5 \\
Penny & Tulip & 24 & 2 \\
Karyn & Rose & 15 & 2 \\
Maggie & Lily & 18 & 1 \\
Alan & Orchid & 13 & 1 \\
Sam & Carnation & 25 & 2 \\
\hline
\end{tabular}

All six master teachers were observed teaching Grade 11 mathematics in their own classrooms. Each master teacher was observed and video recorded at least three times.

\section{Learners}

A focus group interview (FGI) was conducted with selected learners of each of the schools in the final sample of the main study. Learner selection was based on the learners' level of interaction during the observed lesson. Each focus group comprised of learners that interacted frequently in class, learners that did not interact frequently and learners that did not interact at all. These interactions encompassed interactions with both the master teacher and other learners within the classroom.

\section{Ethical considerations}

The Research Officer at the KZN DOE was contacted via e-mail and a copy of the proposal was posted for perusal. Once gatekeeper clearance was granted by the KZN DOE, ethical clearance from the university's research office was applied for. Before the pilot and main studies were conducted, principals of the selected Dinaledi schools were informed of the study and processes that would be followed. Subsequently each master teacher and learner who participated in the study was provided with an introductory letter. This letter discussed and defined informed consent, the right to withdraw and confidentiality. It also provided each participant with the reasons and purpose of the research. Each participant was required to provide their written consent. In the case of the learners, their parents or legal guardians were required to provide written consent. Pseudonyms were used to protect the identity of the schools, teachers and learners.

\section{Research instruments or methods}

The master teacher questionnaire (MTQ) was a structured penand-paper instrument divided into three main sections. These sections included the school profile, the school infrastructure and the master teacher profile. Before the pilot test was conducted, the MTQ was peer reviewed with colleagues working within similar research areas. After minor editing, the MTQ was pilot tested with ten master teachers. I went to each school to administer the MTQ. I asked the master teachers to complete the MTQ at home, because I wanted to provide them with enough time to reflect on what they did in the classroom. I collected the questionnaires after three to five days, after the teachers had informed me that they had completed them. After some additional minor adjustments during the pilot testing phase, the MTQ was administered to the remaining group of ten master teachers in the main study. 
I analysed each MTQ by using a thematic coding process, and selected a purposive sample for the study. Some of the themes used for coding were: resources used, teaching strategies, school infrastructure, teacher professional development, qualification levels of the teacher, teaching experience of teacher and class size. The selection of the final sample of six master teachers was based on their in-depth responses and diverse teaching strategies as mentioned in their questionnaire responses.

The second research instrument that I used was an observation schedule. The observation schedule included a checklist of common visual tools (i.e. diagrams, symbols, gestures, calculators, charts, pictures, mathematics manipulatives, and the use of colour) and the frequency of their use during each lesson. The observation schedule also had an additional blank space at the end of the schedule to add other visual tools that were used by each master teacher. Part of the observation schedule afforded me the opportunity to describe how each visual tool was used during the lesson.

After each lesson observation, I analysed the video recording and notes from each observation schedule. I looked at instances where the teacher used a visual tool to assist in the effective teaching and learning of mathematics. In some instances the teacher brought in a visual tool. Maggie, for example, brought in an overhead projector transparency that she had prepared because of a class discussion during her previous mathematics lesson. This was evidence that she had reflected on her previous lesson (reflection-on-action). In other instances the teacher created a visual tool 'on the spur of the moment'. For example, Alan realised during his lesson on transformation geometry that learners were confused about the terms 'reflection' and 'rotation'. He then used his body as a visual tool to explain the term 'rotation' (an example of reflection-in-action). These examples of the teachers reflecting on and in action helped me in my planning for the next lesson observation; I knew what I needed to be aware of.

At the end of the three lesson observations, each master teacher was given a copy of the video recordings. This assisted the master teacher in preparing for the master teacher interview (MTI). I used semi-structured interviews in the study. I asked each master teacher a few basic questions to start off the interview and then based the rest of the interview on the master teacher's responses on their use of visual tools within the classroom. At least six video clips of specific visual tool use were shown during each interview. These clips were used to remind each master teacher of the visual tools he or she had used. This prompted the master teacher to talk about the reason for the choice of visual tool, how he or she had thought it would help the learners during that specific lesson and whether or not the visual tool had been planned before the lesson or had been developed whilst the master teacher reflected in action.

After each MTI had been analysed, focus group interviews (FGIs) were set up with groups of learners at each of the six schools. The selection of the focus group participants was based on their level of interaction during each lesson. Video recordings of lessons were shown to each focus group. I asked the learners to focus on specific clips from each observed lesson and discussions ensued. The discussions revolved around the learners' interpretations of each master teacher's use of visual tools. I used these discussions to assist me in answering the research questions.

Essentially Table 2 encapsulates the data collection process.

\section{Reliability and validity}

The instruments were carefully designed and pilot tested. Prior to pilot testing the instruments were circulated and discussed with colleagues within the same research area. The language used was basic and appropriate for the master teachers as well as the learners.

The participants were from all parts of $\mathrm{KZN}$ and hence it could be presumed that the responses of these master teachers were representative of the responses of master teachers with similar backgrounds and qualification levels. However, no broad generalisations are made. At every step of the research process, data were analysed and coded using thematic coding. The possibilities of lurking variables were investigated before final coding themes were identified.

\section{Findings and discussion Why do master teachers use visual tools?}

The master teachers in the sample were selected because they used visual tools in most of their mathematics lessons. This information was obtained from the MTQ. In order to address the first research question we will look at the results of the data collected. Evidence obtained in the study suggests that the key reasons why master teachers used visual tools in mathematics classrooms were to ensure that the mathematics became:

- easier to remember

- more interesting and fun

- more concrete, accessible and comprehensible.

TABLE 2: The data collection process.

\begin{tabular}{|c|c|c|c|}
\hline Research question & Participants & Method & Research instrument \\
\hline $\begin{array}{l}\text { Why do master teachers use visual tools in mathematics } \\
\text { classrooms? }\end{array}$ & $\begin{array}{l}\text { Master teacher } \\
\text { Learners }\end{array}$ & $\begin{array}{l}\text { Classroom observations ( } 3 \text { ) } \\
\text { Watching video recordings of master } \\
\text { teachers' lessons } \\
\text { Interviews with master teachers (1) } \\
\text { Focus group interviews with learners (1) }\end{array}$ & $\begin{array}{l}\text { Observation schedule } \\
\text { Master teacher interview schedule } \\
\text { Master teacher questionnaire } \\
\text { Focus group interview schedule }\end{array}$ \\
\hline $\begin{array}{l}\text { How do master teachers use visual tools in mathematics } \\
\text { classrooms? }\end{array}$ & Master teacher & $\begin{array}{l}\text { Classroom observations ( } 3 \text { ) } \\
\text { Field notes } \\
\text { Video recordings of mathematics lessons }\end{array}$ & $\begin{array}{l}\text { Observation schedule } \\
\text { Master teacher interview schedule } \\
\text { Focus group interview schedule }\end{array}$ \\
\hline
\end{tabular}




\section{Making mathematics easier to remember}

Penny used concrete objects to make abstract mathematical concepts more relevant and memorable to the learners. She did not use expensive visual tools, but chose to use tools that were easily accessible to learners in her school. She used different colours on the board, charts, pictures and gestures. Whilst teaching the parabola she used smiley faces and sad faces. She believed that when learners were exposed to these symbols in future lessons, they would remember, on reflection, what the symbols signified. She explained that: '... children remember it ... I use it for that purpose expecting them to remember' (MTI, 25 June 2009).

Similarly, Maggie used symbols that her learners had been exposed to in previous lessons or grades. She explained her reasons for using the symbol that represented a 90 degree angle as follows: '... the standard symbol that we use in Geometry ... it is something that is standard and you learn and remember from grade 8' (MTI, 05 August 2009).

Dean also used visual tools to assist learners to remember rules: '.. if they [the learners] can remember the rule ... by showing them [the learners] the rotation ... the learner sees ... how the position changes' (MTI, 26 June 2009).

Alan's learners were of the opinion that the use of visual tools helped them to remember the mathematics they were taught. This was evident in the following excerpt taken from the FGI with learners:

Learner 6: In the exams it is easier to remember stuff and to study. Sometimes the rules are so close that one can easily misinterpret it for the next rule and by having a diagram we can actually pinpoint which is the exact rule. (FGI, 13 August 2009)

\section{Making mathematics more interesting and fun}

In Karyn's lessons she wanted to prevent her learners from becoming bored or losing interest. She used her visual tools to assist her in this. This was evident from three separate responses:

... here again they need to visualise it, to see it ... if you just talk to them they might fall asleep.

... it might be boring ... I think if you point you can just get their attention ... this is what I am talking about.

... to make the lesson more interesting. (MTI, 18 June 2009)

In the excerpts above, Karyn was referring to her use of gestures and different colours in her mathematics lessons. Sam had a similar notion; he claimed that he used diagrams '... to make the lesson more interesting ...' '(MTI, 02 July 2009).

\section{Making mathematics more concrete, accessible and comprehensible}

With the concretisation of abstract mathematics concepts, mathematics becomes more comprehensible. For example, Dean was teaching a section in transformation geometry where he wanted to show learners how to rotate two points $90^{\circ}$ about the $y$-axis. He used a stick with coloured rubber bands when he demonstrated the direction the learners needed to rotate the points A and B. This was a tool that was easily accessible within the context of the school. Using the stick with the coloured bands, Dean indicated where the new points would be located after the transformation. Dean demonstrated the rotation 'on the spot'; he developed this concrete visual tool when he realised that his learners were having a problem with understanding the concept of rotation. Dean wanted to make the mathematics he taught concrete and more accessible to his learners and so he reflected-inaction.

By using a simple visual tool, he managed to make an abstract concept concrete so that the learners could come to grips with it. This was evident from the following learner comment:

Learner 5: If he [Dean] hadn't used the stick ... then we would have been confused, we would not have known which direction we were moving in [the direction of rotation]. (FGI, 25 August 2009)

Once he had completed his demonstration, Dean prompted his learners to try to solve the initial task. Evidence obtained in the study showed that they were able to solve the problem successfully.

In another example that occurred in Dean's classroom, Dean highlighted parts of a diagram on the board by using coloured chalk. He did this to make the mathematics more comprehensible and visible. This was evident from what Dean later said during the interview:

I think that it is beneficial ... I highlighted only certain parts ... so they [the learners] know exactly which parts are undergoing some transformation ... instead of giving them just a set of notes ... they can see exactly which part we are manipulating. (MTI, 26 June 2009)

Alan also used tools that were inexpensive and easily accessible, such as paper, coloured chalk and his body. Alan's learners commended their teacher on using visual tools because they felt that visual tools helped them. This was evident in the following transcript taken from the FGI:

Learner 3: It becomes much easier to grasp, the diagram was ... helpful. (FGI, 13 August 2009)

\section{How do master teachers use visual tools?}

In order to address the second research question, we will look at the results of the data collected. Master teachers used visual tools in the mathematics classrooms as a scaffolding technique. Scaffolding teaching and learning through the use of visual tools in mathematics classrooms recasts the relationship between what teachers teach and how they teach. It foregrounds the fact that the ways in which teachers teach and the ways in which learners learn are inextricable aspects of the classroom culture. The master teachers showed evidence of reflecting in action as well as reflecting on action when using visual tools in the classroom. For example, Alan used his experience of what worked and what did not work when he prepared his lessons. He displayed evidence of reflecting on action: 
... I learnt ... if something doesn't work in the first class I will try something else ... in the second class. (MTI, 06 August 2009)

The classroom observations, video recordings, the MTI and the FGI provided evidence that, rather than using direct teaching strategies or the traditional approach to teaching mathematics (chalk and talk), each master teacher incorporated scaffolding techniques to support their learners' development in mathematics (see also Naidoo, 2011b). They did so without any training or urging from the researcher. Anghileri (2006) distinguished three levels of scaffolding. The three levels are explained below.

\section{Level 1: Organising the learning environment}

Level 1 scaffolding relates to the manner in which the teacher organises the learning milieu. This organisation may include the use of pictures, charts, seating arrangements and peer collaboration. For example, whilst teaching the different types of graphs (hyperbolas, exponential graphs and parabolas), Penny decided to divide her class into smaller groups. Penny provided each group with chart paper and asked them to answer different problems on the chart paper. She then asked each group to present their solutions. In Penny's classroom the learning environment was reorganised to accommodate active peer collaboration to scaffold the teaching and learning of mathematics. This was evident from her response in the MTI:

The aspect of group work helps those that are not picking up the concepts easily ... It helps to encourage peer learning ... learners presented their work on charts which is visual as well. So they get to see it. (MTI, 25 June 2009)

Penny used charts as a manipulative that encouraged learners to work collaboratively within a visual environment. The use of learner centred approaches to learning promotes the development of higher order skills such as critical thinking and problem solving (Brush \& Saye, 2002). Learners were also encouraged to work collaboratively with one another and discuss their ideas in front of the class. This strategy reinforces the importance of peer learning because it provides learners with the confidence to talk about mathematics. The strategy also gives learners the opportunity to become a part of a group where they feel supported and validated (Dodge \& Kendall, 2004). Penny knew from past experience that group work was important for teaching and learning, and she prepared this activity, which involved both group work and the use of a visual tool (a chart), before coming into the classroom. She planned in advance to create a group work activity and environment in order to ensure effective teaching and learning of graphs in algebra. During our discussion of her group work activity, Penny showed evidence of reflecting-on-action.

The next level of scaffolding revolves around the interactions within the classroom, specifically the interactions that occur between the teacher and learner.

\section{Level 2: Exploring teacher-learner interaction}

When teachers demonstrate, discuss and explain concepts to their learners, learners do not always find it easy to comprehend these concepts. To assist in alleviating this challenge, learners and teachers need to interact with each other, and there needs to be collaboration between all members of the learning community. Scaffolding at Level 2 includes different levels of teacher-learner interaction. This kind of interaction relies on the teacher reviewing and restructuring what is happening in the classroom and therefore requires the teacher's reflecting-in-action. Level 2 scaffolding may be represented diagrammatically as shown in Figure 1.

As can be seen in Figure 1, scaffolding at Level 2 incorporates two major aspects: reviewing and restructuring.

Reviewing consists of two subsets. The first subset involves the teacher looking, touching and verbalising what is required. This then progresses to parallel modelling. Parallel modelling refers to instances where the teacher identifies learner misconceptions and misunderstandings, creates tasks that share characteristics with the learners' problem and then solves the tasks in collaboration with the learners (Anghileri, 2006).

The second subset of reviewing involves the teacher using probing as well as prompting techniques. This is followed by the learners explaining and justifying their ideas. Subsequently the teacher interprets the learners' actions and discussions. There was evidence of prompting in Dean's classroom, as he used gestures to prompt learners to use the correct keys when they used the calculator. When questioned about the use of his gestures, Dean showed evidence of reflecting-in-action. During the lesson he realised that the learners were having a problem with the use of the calculator, and so he immediately used gestures to demonstrate the correct sequence of keys to be used. In the MTI he stated:

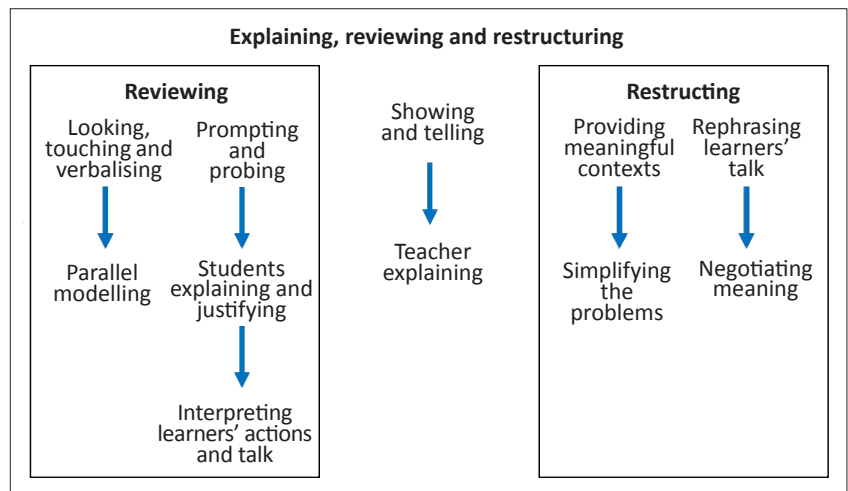

Source: Anghileri, J. (2006). Scaffolding practices that enhance mathematics learning. Journa of Mathematics Teacher Education, 9, 33-52. http://dx.doi.org/10.1007/s10857-006-9005-9 FIGURE 1: Teacher strategies for scaffolding learning at Level 2. 
It's the force of habit, I am not aware that I am doing this [using gestures] ... when I did this [he used the sign language of a bracket during the interview] then they [the learners] can see it ... that's how it is on the calculator so they know which key to press. (MTI, 26 June 2009)

During the reviewing process, learners ought to be encouraged to verbalise what they see and think. The learners need to be motivated to explain and justify their actions and comments. Through interpretation of learner comments, prompting and asking probing questions, teachers have a higher probability of identifying misconceptions and misunderstandings in mathematics thinking and learning.

This was evident in Karyn's classroom when she asked her learners to find the perimeter of a triangle. As she spoke to the learners she realised that they did not understand what was required of them. Karyn explained her reasons for probing and the use of gestures as follows:

To make sure that they know what is perimeter ... if you use a word make sure that they understand what you are talking about. They always get confused between the perimeter and area. (MTI, 18 June 2009)

The above transcript shows evidence of Karyn restructuring and reviewing her questions and discussion in class to ensure that what she was teaching became more comprehensible to the learners. This demonstrated that Karyn was reflecting-inaction; she did this 'on the spur of the moment'.

As discussed earlier, parallel modelling occurs after touching, looking and verbalising. Karyn used parallel modelling when she used examples similar to the ones learners had a problem with. She did this when she reviewed; she solved problems until the problem-solving process made sense to her learners. She formulated problems and examples from her learners' comments. For example, whilst Karyn was teaching analytical geometry she placed a question on the board for her learners to attempt. In order to assist her learners she prompted and probed learner responses by asking key questions. This is evident from the observation transcripts:

Karyn: What is the restriction for $\mathrm{N}$ and $\mathrm{M}$ ?

Learner 1: $\quad$ They must be an equal distance apart.

Karyn: Class, the suggestion is that they must be equal distance apart. How can we make sure of this?

Learner 2: $\quad$ Calculate the distance of MP and NP; they must be the same. (OBS 1, 18 March 2009)

Karyn used deictic gestures and supported her learners' understanding of tasks by operating from her learners' ideas. Once Karyn was confident that her learners could work on their own, she allowed them to work independently. Karyn reflected in action because the lesson developed as the learners interacted with her.

In Figure 1 two subsets to restructuring in the classroom are also shown. The first subset requires the teacher to provide meaningful contexts which then leads to the next level, where the problems are simplified. The second subset of restructuring tasks involves rephrasing what the learner says, which leads to the level of negotiating meanings. In my study I found that whilst the master teachers were in control, as is common with traditional approaches to teaching (chalk and talk), they also involved their learners in the discussion. They reviewed and restructured tasks to accommodate their learners' needs.

This was evident in Maggie's lesson on calculating areas, for example. She used her mathematical language to serve as a scaffold to the teaching and learning of mathematics. Whilst this is what is expected in a mathematics classroom, the manner in which Maggie used the register of mathematics stood out. She made the register of mathematics meaningful. Maggie started by talking about the area of triangles. She then asked her learners to think about calculating the area of triangles (this is generally taught in earlier grades). She provided a meaningful context by reminding learners of the mathematics they had been exposed to previously. She spoke about perpendicular lines; the base of triangles, the heights of triangles and the vertex of the triangle. She punctuated her words with deictic gestures.

This was also evident in Penny's classroom. When Penny taught parabolas, she wanted to teach her learners a method for remembering the shape of the parabola. Through discussion, Penny and the learners negotiated to use facial gestures to signify the shape of the parabola. A smile signified that the coefficient of $a$ in the function $y=a x^{2}+b x+c$ was positive and a frown signified that the coefficient of $a$ in the function $y=a x^{2}+b x+c$ was negative. Through her rephrasing of what learners had articulated and through negotiating meaning, she helped the learners to remember the shape of the parabola, based on the sign of the coefficient of $a$. Whilst this is not something new, Penny and her learners also negotiated the notion that the change in shape was prompted by a change in the value of the coefficient of $a$.

In another example that occurred in Alan's classroom, Alan used a sheet of paper to represent the Cartesian plane; he negotiated and mediated meaning in his classroom to achieve his outcomes. He expected his learners to use this manipulative to transform, reflect and rotate coordinates about the $x$-axis and $y$-axis. He reflected-in-action and used the sheet of paper as a visual tool to facilitate understanding. After demonstrating, parallel modelling and probing, his learners comprehended the different transformations, according to the evidence in the video recordings of his lesson.

When restructuring tasks, the teacher simplifies the problem or rephrases the learners' comments with the aim of negotiating meanings and advancing understanding. Meaningful contexts are created so that abstract situations become more accessible to the learner. During a trigonometry lesson, for example, Karyn used the context of flying. This context was meaningful and useful to the learners as can be seen in the following:

Learner 4: We are doing trigonometry in maths and we did an example with an aeroplane so even in maths we are learning how to apply why they use trig and why we need trig. 
Learner 8: When she [Karyn] uses things like reality stuff then it makes me understand more better ... with real life examples it makes it [mathematics] easier to understand. (FGI, 21 August 2009)

One of Maggie's learners commented on another example that the teacher had used:

Learner 1: As she [Maggie] is going along she will draw the triangle and she will say like point $\mathrm{A}$ and then she would redo point $A$ and point $B$ and point $C$ and then as she goes along explaining what she does she redraws the triangle basically with either the same colour or even with a different colour, she is actually redoing line $\mathrm{AB}$ just to emphasise that this is the line that you will use and these are your measurements. (FGI, 19 August 2009)

\section{Level 3: The use of representational tools}

Level 3 scaffolding refers to the use of representational tools with the aim of generating conceptual discourse within the classroom (Verenikina \& Chinnappan, 2006). These tools assist in making abstract mathematics more accessible to learners. For example, Alan used a sheet of paper to represent the Cartesian plane. During his discussion with his learners he taught them how to transform shapes about the $x$-axis and $y$-axis via the use of this representational tool. The abstract concept of reflection was taught by using fold lines on the sheet of paper. Alan's choice of using the paper came as a result of his reflecting-in-action. During the MTI and after being shown the video clip of him using this sheet of paper, Alan said that whilst he was teaching this lesson he realised that learners did not understand the concept of reflecting shapes about the axes, so he decided to use a hands-on example to help them.

Dean used a stick with coloured rubber bands to make the abstract concept of rotation more accessible to his learners. During the MTI Dean maintained that he had used this visual tool 'on the spur of the moment'. This comment illustrates evidence that Dean reflected-in-action to advance the effective teaching and learning of mathematics.

\section{Conclusion}

From the data collected it was evident that the master teachers used visual tools to make the mathematics that they taught easier to remember, interesting and fun. Additionally, the master teachers wanted to make the mathematics they taught concrete, accessible and comprehensible. In order to achieve their aims, each master teacher used different levels of scaffolding techniques during their lessons. This study also emphasised the importance of teacher reflection in using visual tools to assist learners in understanding mathematical concepts. Visual tools were used in different contexts in order to advance the teaching and learning of mathematics. The evidence gathered in the study showed that most of the visual tools that were used were accessible and inexpensive. They were tools that could be obtained and used within any social context.
The use of the visual tools were either planned before the lesson or created during the lesson. This study also illustrated that each master teacher successfully engaged their learners in the classroom by using visual tools. As a result of the use of visual tools, the learners were not merely passive recipients, but active participants. Meanings were constructed in the classrooms through negotiation with the classroom community. There was constant interaction between the teachers and learners within the classroom community. This study also demonstrated that whilst scaffolding has become useful for teachers (Verenikina \& Chinnappan, 2006), the purpose of scaffolding is to provide learners with a teachersupported transition. This implies that after learners had looked at and listened to the teacher, as he or she illustrated a particular mathematical concept, they could then be required to perform the skill independently. However, whilst the use of scaffolding in mathematics is necessary, scaffolding is useless on its own. It is necessary that scaffolding be complemented by mathematical understanding, together with the ability to think, perceive and analyse mathematically (Lewis, 2010). This mathematical understanding is achieved through constant teacher-learner interaction and visual tool use.

This study further demonstrated that an effective teacher does not rely on the traditional 'chalk and talk' methods only, but is a facilitator who values the power of tangible teacherlearner interaction. Through the use of visual tools, well planned interactions, reflecting in and on action, effective teaching and learning of mathematics may be promoted in any classroom regardless of context. However, it is imperative that the teacher chooses each visual tool carefully, taking into account the exact outcome he or she has in mind.

\section{Limitations and recommendations for future work}

Based on evidence obtained in this study, the use of visual tools in mathematics classrooms has proved to be beneficial; it is recommended that pre-service and in-service institutions provide teachers on-going support in this area.

This study explored master teachers' use of visual tools in one province of South Africa; it is therefore recommended that further research be conducted which focuses on exploring the use of visual tools in other provinces in South Africa.

This study has provided valuable data; however, one limitation involves a technical aspect. It would probably have been beneficial to use two video cameras, one directed at the master teacher and one focused on the learners. This would have captured the learners' responses and expressions, especially in situations that were considered critical moments in each lesson. This would also have captured relevant learner responses when the master teacher resorted to using visual tools whilst reflecting-in-action.

\section{Implications for professional development}

The teaching and learning of mathematics through the use of visual tools is a useful strategy for teachers teaching 
in schools in different locations and contexts. This study foregrounds teacher reflection via the use of visual tools. To assist in promoting the use of visual tools, teacher educators ought to provide training to both in-service and pre-service teachers on the use of visual tools in the classroom with the aim of advancing the effective teaching and learning of mathematics. To do this teacher educators need to understand and value the importance of teacher reflection.

\section{Acknowledgements}

I would like to thank the University of KwaZulu-Natal for funding this study (Doctoral Research Grant and Competitive Grant). The opinions expressed here are those of the author and do not necessarily reflect the position, policies or endorsements of the university.

\section{Competing interests}

No financial or personal relationship(s) have inappropriately influenced the writing of this article.

\section{References}

Adler, J. (2001). Resourcing practice and equity: A dual challenge for mathematics education. In B. Atweh, H. Forgasz, \& B. Nebres (Eds.), Sociocultural research on mathematics education. An international perspective (pp. 185-200). Mahwah, New Jersey: Lawrence Erlbaum Associates.

Anghileri, J. (2006). Scaffolding practices that enhance mathematics learning. Journa of Mathematics Teacher Education, 9, 33-52. http://dx.doi.org/10.1007/s10857of Mathematic

Ball, D.L., Lubienski, S.T., \& Mewborn, D.S. (2001). Research on teaching mathematics: The unsolved problem of teachers' mathematical knowledge. In V. Richardson (Ed.), Handbook of research on teaching (4th edn.) (pp. 433-456). New York, NY: Macmillan.

Barnes, H. (2005). The theory of realistic mathematics education as a theoretical framework for teaching low attainers in mathematics. Pythagoras, 61, 42-57. Available from http://www.pythagoras.org.za/index.php/pythagoras/article/ view/120

Breen, C. (1997). Exploring imagery in P, M and E. In E. Pehkonen (Ed.), Proceedings of the 21st Conference of the International Group for the Psychology of Mathematics Education, Vol. 2 (pp. 97-104). Lahti, Finland: University of Helsinki.

Brush, T.A., \& Saye, J.W. (2002). A summary of research exploring hard and soft scaffolding for teachers and students using a multimedia supported learning environment. Journal of Interactive Online Learning, 1(2), 1-12. Available from http://www.ncolr.org/jiol/issues/pdf/1.2.3.pdf

Chisholm, J.S., \& Sujee, M. (2006). Tracking racial desegregation in South African schools. Journal of Education, 40, 141-159. Available from http://dbnweb2.ukzn. ac.za/joe/JoEPDFs/joe\%2040\%20chisolm\%20and\%20sujee.pdf

Department of Basic Education. (2011a). Mathematics. Curriculum and assessment policy statement. Grades 10-12. Pretoria: Department of Basic Education.

Department of Basic Education. (2011b). Mathematical Literacy. Curriculum and assessment policy statement. Grades 10-12. Pretoria: Department of Basic Education.

Department of Education. (2003a). National curriculum statements. Grades 10-12 (General) Mathematics. Pretoria: Department of Education.

Department of Education. (2003b). National curriculum statement. Grades 10-12 General) Mathematical Literacy. Pretoria: Department of Education.
Department of Education. (2008). National curriculum statement. Grade 10-12. NSTF workshop (pp. 1-31). Pretoria: Department of Education.

Dodge, L., \& Kendall, M.A. (2004). Learning communities. College Teaching, 52(4), 150-155. http://dx.doi.org./10.3200/CTCH.52.4.150-155

Elia, I., \& Philippou, G. (2004, July). The functions of pictures in problem solving Paper presented at the the 28th Conference of the International Group for the Psychology of Mathematics Education, Bergen.

Freire, P. (1985). The politics of education, culture, power, and liberation. London: Macmillan.

Handal, B., \& Bobis, J. (2004). Instructional styles in the teaching of mathematics thematically. In D. Burghes, \& T. Szalontai (Eds.), International monograph on
mathematics teaching worldwide: Monograph (pp. 1- 8). Budapest: Wolters mathemat
Kluwer.

Howie, S.J. (2003). Language and other background factors affecting secondary pupil's performance in mathematics in South Africa. African Journal of Research in Mathematics, Science and Technology Education, 7, 1-20.

Kahn, M. (2004). For whom the school bell tolls: Disparities in performance in senior certificate mathematics and physical science. Perspectives in Education, 22(1), 149- 56.

Lewis, R.H. (2010). Mathematics. The most misunderstood subject. Fordham University. Available from http://www.fordham.edu/academics/programs_at_ fordham_/mathematics_departme/what_math/

Makapela, L. (2007). Dinaledi schools making progress. South Africa.info. Available from http://www.southafrica.info/about/education/dinaledi-161007.htm

Naidoo, J. (2006). The effect of social class on visualisation in geometry in two KwaZulu-Natal schools, South Africa. Unpublished master's thesis. University of Nottingham, Nottingham, UK.

Naidoo, J. (2011a). Exploring master teachers' use of visuals as tools in mathematics classrooms. Unpublished doctoral dissertation. University of KwaZulu-Natal, Durban, South Africa.

Naidoo, J. (2011b). Scaffolding the teaching and learning of mathematics. In H. Venkat, \& A.A. Essien (Eds.), Proceedings of the 17th Annual National Congress of the Association for Mathematics Education of South Africa, Vol. 1 (pp. 124-134). Johannesburg: AMESA. Available from http://www.amesa.org.za/AMESA2011/ Volume1.pdf

Preen, C. (2007). AAPA guide to reflective practice. Reflection handbook. London: AAPA publishers.

Putnam, R.T., \& Borko, H. (2000). What do new views of knowledge and thinking have to say about research on teacher learning? Educational Researcher, 29(1), 4-15. http://dx.doi.org/10.3102/0013189X029001004

Reddy, V. (2005). State of mathematics and science education: Schools are not equal. Perspectives in Education, 23(3), 125-138.

Remillard, J.T. (2005). Examining key concepts in research on teacher's use of mathematics curricula. Review of Educational Research, 75(2), 211-246. http:// dx.doi.org/10.3102/00346543075002211

Roodt, J., \& Conradie, P. (2003). Creating a learning culture in rural schools via educational satellite television broadcasts. Communicatio, 29(1/2), 265-279. http://dx.doi.org/10.1080/02500160308538031

Schön, D.A. (1983). The reflective practitioner: How professionals think in action. New York: Basic Books.

Schön, D.A. (1987). Educating the reflective practitioner. San Francisco, CA: JosseyBass.

Soudien, C. (2004). 'Constituting the class': An analysis of the process of 'integration' in South African schools. In L. Chisholm (Ed.), Changing class: Education and socia change in Post-Apartheid South Africa (pp. 89-114). London: Zed Books.

Stokes, S. (2000). Visual literacy in teaching and learning: A literature perspective. Electronic Journal for the Integration of Technology in Education, 1(1), 10-19.

Ursano, A.M., Kartheiser, P.H., \& Ursano, R.J. (2007). The teaching alliance: A perspective on the good teacher and effective learning. Psychiatry, 70(3), perspective on the good teacher and effective lea
187-194. http://dx.doi.org/10.1521/psyc.2007.70.3.187

Verenikina, I., \& Chinnappan, M. (2006, July). Scaffolding numeracy: Pre-service teachers' perspective. Paper presented at the 29th Conference of the Mathematics Education Research Group of Australasia (MERGA), Canberra.

Wentzel, K.R. (2002). Are effective teachers like good parents? Teaching styles and student adjustment in early adolescence. Child Development, 73(1), 287-301. http://dx.doi.org/10.1111/1467-8624.00406 